\section{Biochemical terrorism: too awful to contemplate, too serious to ignore}

\author{
Subjective literature review \\ DAVID ALAN ALEXANDER and SUSAN KLEIN
}

\begin{abstract}
Background It is important not to foster unnecessary public anxiety with regard to the risk of a biochemical terrorist incident, but the authorities need to consider their response strategy, particularly with regard to mental health issues.
\end{abstract}

Aims To describe the likely effects of a terrorist incident involving biochemical agents and to identify important response issues.

\section{Method Literature survey. \\ Results Observations following conventional terrorist incidents and other major trauma, including biochemical and nuclear accidents, suggest that a \\ biochemical terrorist incident would have widespread public effects. The mental health services should play a major role in designing an effective multi-disciplinary response, particularly with regard to the reduction of public anxiety, identifying at-risk individuals and collaborating with medical and emergency services, as well as providing care for those who develop post-traumatic psychopathology.}

\section{Conclusions We should not feel} helpless in the face of a biochemical threat; there is considerable knowledge and experience to be tapped. A well-designed, well-coordinated and rehearsed strategy based on empirical evidence will do much to reduce public anxiety and increase professional confidence.

Declaration of interest None.
Particularly since the tragedies of 11 September 2001, much has been said and written about the risk of a biochemical terrorist attack. If one pares away the hyperbole and unnecessary drama that this issue has attracted, the exposed conclusion is that the risk is genuine and the consequences would be serious. What used to be a theme of a genre of horror films and novels has been recast as a real phenomenon of the 21st century. This represents a major challenge with regard to designing an effective strategy for coping with the aftermath of such an attack. This paper will address some of the major issues in relation to a biochemical terrorist attack, including the aims of such terrorism, its likely psychological effects and the possible intervention strategies to mitigate such effects.

\section{BACKGROUND}

The US Department of Justice defines terrorism as

\footnotetext{
'the unlawful use of force or violence against persons or property to intimidate or coerce a government, the civilian population, or any segment thereof, in furtherance of political or social objectives' (US Department of Justice, 1996).
}

What we consider to be unjustifiable and repugnant acts of terrorists are viewed by the perpetrators as rational and may be allied to cherished martyrdom. Post (2002) has argued that an understanding of the motivations of terrorists can help their victims to make some sense of their suffering.

The authorities are not able to calculate accurately the risk of such terrorist activity, but it is important that forewarning and preparation are not on such a scale that massive public anxiety is created, because this would serve well the aims of the terrorists by creating a nation of 'terro-phobes'. To achieve a balanced approach, and to design an effective strategy for responding to biological or chemical terrorism, the mental health services have much to offer because, as will be argued below, biochemical terrorism is 'quintessentially psychological warfare' (Wessely et al, 2001).

Historically, terror has proved to be an effective instrument of coercion and intimidation for state organisations such as the Tzarist Okrahana, the Nazi Geheime Staatspolizei (the Gestapo), and the East German Ministerium für Staatssicherheit (the Stasi) and other groups with a specific agenda, such as the Mafia and the Ku Klux Klan. The political activities of the BaaderMeinhof Group, the Irish Republican Army, the Algerian Salafis, the Basque Homeland and Liberty Group (ETA) and the al Qa'ida have underscored just how effective the use of terror can be, at least in the short term. Most recently, 'suicide terrorism' has caused profound fear and social disruption (Salib, 2003). However, we must maintain a realistic perspective; sometimes their efforts are not successful and may be counterproductive (Laqueur, 1999).

\section{AIMS OF BIOCHEMICAL TERRORISM}

The literature identifies the following aims:

(a) creating mass anxiety, fear and panic;

(b) creating helplessness, hopelessness and demoralisation;

(c) destroying our assumptions about personal security;

(d) disruption of the infrastructure of a society, culture or city;

(e) demonstrating the impotence of the authorities to protect the ordinary citizen and his/her environment.

The aims of terrorism do not require massive casualties for their fulfilment: death and physical damage is a means to an end, not an end in itself. Following the two attacks using the nerve gas sarin in the Japanese cities of Matsumoto (1994) and Tokyo (1995), carried out by the Aum Shinrikyo cult, only 19 deaths occurred but the psychological, social and economic effects of these incidents were enormous (Knudson, 2001).

\section{ATTRACTION \\ OF BIOLOGICAL AND CHEMICAL AGENTS}

'Conventional' terrorism made use of explosive and standard weaponry, but the authorities made access to such items more 
difficult and, as society adjusted to previous levels of violence and atrocity, terrorists have had to seek methods of achieving an even higher level of threat. Although there are impediments to their use, including storage and dispersal (Venkatesh \& Memish, 2003), biological and chemical agents generally commend themselves to terrorists for at least six reasons:

(a) it is relatively easy to obtain information about them;

(b) many agents are relatively cheap and easy to produce, and can be delivered without high technology or much scientific knowledge (Smith, C. G., et al, 2000);

(c) although there have been considerable advances in the scientific understanding of the most lethal (Category A) biological agents such as Variola major (smallpox), Bacillus anthracis (anthrax) and Yersinia pestis (plague) and highly toxic (Category B) chemicals such as ricin toxin, there is much to be learned about their effects and how to combat them (Arnon et al, 2001; Lane et al, 2001);

(d) the effects, particularly of biological agents, are commonly distant in time and place from the site of any initial incident;

(e) because viruses and microbes, and some toxic chemicals, cannot be detected through the senses they readily instill fear and trigger powerful vestigial fears of mysterious threatening forces;

(f) particularly with biological agents, there is no clearly defined 'low point' from which survivors and their caregivers can look forward to respite and improvement (Baum, 1986).

\section{PSYCHOLOGICAL REACTIONS TO A BIOCHEMICAL INCIDENT}

There is no absolute certainty as to how individuals and communities would react following such an incident in the UK. Thus, we need to cull from our knowledge relating to other major calamities (e.g. Piggin \& Lee, 1992; van der Kolk et al, 1996; Joseph et al, 1997), 'conventional' terrorist events (e.g. Sims et al, 1979; Alexander, 2001; Schuster et al, 2001), nuclear accidents (Houts et al, 1988; Allen et al, 1996) and military campaigns in which toxic agents have been deployed (e.g. Fullerton \& Ursano, 1990).

\section{Community reactions}

Tyhurst (1951) suggested that, following a major trauma, there is likely to be a triphasic response. In the initial 'impact', survivors will be preoccupied with their present situation and most will be stunned and numbed. Up to about $15 \%$ will still be able to retain their ability to think rationally, to evaluate the level of risk and to take appropriate action. During the 'recoil' phase, survivors will want to talk to others and seek support. The reality of what has occurred becomes irresistibly obvious to survivors at the 'post-trauma' phase. It is similar to the 'post-honeymoon' phase described by Raphael (1986) that follows major trauma. During this phase survivors are likely to display a number of emotional reactions, including depression, anxiety and anger (particularly if they consider that their legitimate needs have not been met).

Pennebaker \& Harber (1993) describe a social stage model of collective coping one that emphasises how the need of individuals to talk about their experiences varies over time. Immediately after such an event there is an enthusiasm for sharing views, but that stage is followed by an 'inhibition' phase during which they are more likely to reflect on than talk about the incident.

'Panic' describes a group response in which the impulsive flight reaction is acute and intense, for example when individuals feel completely trapped and lacking control of the situation (Pastel, 2001). It is contagious and results in individuals looking after their own safety and welfare. Panic should not be confused with mass anxiety because the latter can lead to constructive action. To what extent mass panic is likely to occur after a major biochemical terrorist incident remains unconfirmed (Wessely, 2000). In relation to most major catastrophes this has not been shown to be a characteristic reaction (e.g. Quarantelli, 1960; Durodié \& Wessely, 2002). Glass \& Schoch-Spana (2002) also challenge the pessimistic view of community reactions. They argue that the general public are likely to display adaptive, collective action. They advocate that the community should be acknowledged as a 'key partner' in the planning and execution of the medical and public health response to a terrorist incident. More specifically, they propose five guidelines regarding public involvement. These are: treat the public as a competent ally; involve community organisations in public health operations; anticipate the need for home-based patient care and control of infection; invest in public outreach programmes and communication strategies; and ensure that the response strategy reflects the values and attitudes of the communities affected by the incident.

None the less, a biochemical terrorist incident would involve a number of elements that could conduce to overwhelming anxiety and subsequent panic. Ramalingaswami (2001) reported that after the 1994 outbreak of suspected pneumonic plague in Surat, India, there was widespread panic such that overnight approximately 600000 citizens (including medical staff) fled the region.

The short-term effects of a biochemical incident require the authorities to plan for the provision of medical resources, including psychological services. In the longer term a terrorist incident is likely to have more chronic medical and psychiatric sequelae and substantial political and socio-economic effects. Terrorist action in New York and in Bali demonstrate how events on that scale can jeopardise the tourist trade, compromise financial markets and cause governments to review their political agenda. Several authorities have suggested that the longer-term consequences of a biochemical assault may be the more devastating and pernicious (e.g. Becker, 2001; Wessely et al, 2001).

\section{Individual reactions}

Observations following natural and humaninduced major trauma describe a miscellany of individual reactions, although much would depend on the incubation period, virulence and toxicity of the agents used (Holloway et al, 1997). However, these reactions are likely to include the following:

(a) stunned and numb: numbing shields us temporarily from overwhelming images, experiences and emotions;

(b) anxiety and fear: because of their unfamiliarity, biochemical agents would generate high levels of anxiety and fear and challenge our usual methods of coping;

(c) horror and disgust: biochemical incidents would expose the uninitiated to unfamiliar forms of suffering and injury;

(d) anger and scapegoating: the authorities and 'helpers' may be blamed for a failure to protect and care for survivors; 
(e) paranoia: terrorists are characteristically an 'unseen enemy' and their unpredictable attacks are likely to generate a community sense in any community of being persecuted; there may also be xenophobia;

(f) loss of trust: as Janoff-Bulman (1992) pointed out, traumatic events can shatter our core assumptions, including those relating to our safety and vulnerability;

(g) demoralisation, hopelessness and helplessness: a biochemical attack would challenge individuals' internal locus of control such that they would feel as though they were not in charge of their own destiny;

(h) guilt: 'survivor' guilt will be experienced by some who survive a biochemical incident, and 'performance' guilt is likely to be experienced by those who believe that they did not do enough to help others;

(i) false attributions: a lack of understanding about biochemical contamination may cause individuals to attribute falsely normal psychological stress reactions or other benign physical phenomena to the agents used by the terrorists; this has been observed in cases of 'mass psychogenic illness' (Bartholomew \& Wessely, 2002).

\section{MASS PSYCHOGENIC ILLNESS}

This term has been used to describe

'the rapid spread of illness signs and symptoms affecting members of a cohesive group, originating from a nervous system disturbance involving excitation, loss or alteration of function whereby physical complaints that are exhibited unconsciously have no corresponding organic aetiology' (Bartholomew \& Wessely, 2002).

In an excellent review they emphasise the influence of sociocultural factors. Following the events of 11 September 2001, the threat of biochemical terrorism sired the 'anthrax scares' and the 'World Trade Center syndrome' (widespread reports of chest pain and respiratory problems).

A concern is that the medical and welfare services would be overwhelmed in the wake of a major biochemical incident, primarily by many anxious individuals and not just those who had been exposed to contaminants (e.g. Tucker, 1997; Knudson, 2001), as occurred after the radiological contamination incident in Goiania, Brazil, in 1987 (Petterson, 1988). Of the first 60000 screened, 5000 had not been contaminated but all had presented with symptoms of vomiting, diarrhoea and rashes, all of which are consistent with acute radiation sickness. Ultimately, 125800 persons had to be screened but only 249 of them had been contaminated. Knudson (2001), with regard to the Aum Shinrikyo incident in 1995, reported that the ratio of those who sought medical help to those who required immediate medical care was approximately 450:1.

The concept of 'the worried well' appears in the literature (Knudson, 2001) but this term is inaccurate and unhelpful (Pastel, 2001). Such individuals have cause to be anxious and, moreover, the level of anxiety may be such that they are not 'well', at least in psychological terms. Moreover, other authorities (e.g. Engel, 2001) have cautioned against dismissing such health concerns because this is likely to raise suspicions of a conspiracy or of an uncaring or incompetent authority. Hadler (1996) has also suggested that a dismissive approach could result in a 'contest' in which survivors redouble their efforts to persuade doctors of the legitimacy of their symptoms. Engel (2002) refers to a similar dynamic in relation to 'medically unexplained physical symptoms' whereby patients and medical staff can become locked in debate over 'contested causation'.

Engel (2001) has offered some guidelines as to how such individuals should be dealt with. These include the need to offer an empathic, non-judgemental, collaborative approach to help these ailing individuals achieve a better level of adjustment. It is important to note the conclusion of Bartholomew \& Wessely (2002) that none of us is immune from such reactions because there are no clearly defined predispositions to mass psychogenic illness.

\section{PSYCHIATRIC/ PSYCHOLOGICAL SYMPTOMS}

There is a substantial body of epidemiological data that confirms that after major trauma significant levels of psychomorbidity can be expected (e.g. O’Brien, 1998; Harvey \& Bryant, 1999; Fairbank et al, 2000; Alexander \& Klein, 2003). Following terrorist incidents, the rates of psychiatric conditions tend to be quite high, particularly in terms of acute stress disorder, post-traumatic stress disorder, depression and pathological grief (Shalev, 1992; Koopman et al, 1995; Smith, D., et al,
1999). North et al (1999) reported that $34 \%$ of 182 survivors of the Oklahoma City bombing developed post-traumatic stress disorder and that a further $11 \%$ developed other psychiatric conditions, including depression and substance misuse. Schuster et al (2001) conducted a randomdigit-dialling telephone survey 3-5 days after the terrorist attacks of 11 September 2001. Of the 560 adults interviewed, $44 \%$ reported at least one substantial symptom of stress and $35 \%$ of the children had one or more stress symptom. Even 12 months post-incident, increased rates of alcohol and tobacco consumption, stress and posttraumatic stress disorder were reported when compared with a control group comprising citizens of another city.

\section{THE MEDIA}

Following any major biochemical terrorist incident the media will be unavoidably but quickly involved, as has been confirmed by a number of specialists (e.g. Nocera, 2000). The subsequent level of uncertainty and anxiety (for reasons described above) would create a fertile soil in which rumour and ill-informed speculation would thrive, as was seen in the case of hyperbolic headlines about 'flesh-eating bugs' and 'mad cow disease'. The media can resonate with vestigial fears of microbial and viral agents, fears that have been recorded throughout history and particularly during the plague epidemics of the Middle Ages, leprosy and the polio epidemics of the 20th century. Children may be affected adversely by the media coverage of trauma, particularly if they themselves were bereaved as a result of the event (Pfefferbaum et al, 1999).

The media must be embraced by the authorities as allies because, particularly in the early stage after a terrorist incident, they can play a helpful role by broadcasting to an anxious population accurate information about, for example:

(a) what has happened;

(b) what sources of help are available;

(c) what are the signs suggesting that professional help might be required;

(d) what are normal reactions;

(e) what is the difference between contagion and other modes of infection;

(f) the resilience of individuals and communities.

In addition, the authorities can, through the media, address important matters relating 
to, for example, decontamination and isolation procedures, restriction on travel and the disposal of dead bodies. In any multiracial society the last issue is likely to be a delicate one, particularly if cremation and a prohibition on access to the deceased is required, on health grounds, because this may transgress religious and cultural beliefs and values (Speck, 1978; Gibson, 1998).

After so-called 'silent' disasters involving radiation, there has been a temptation for the authorities to avoid releasing information (Green et al, 1994). It was not until 28 April 1986 that the Russian authorities admitted that there had been a nuclear accident at Chernobyl 2 days earlier. Similarly, they displayed a reluctance to give out accurate information after the sinking of their nuclear submarine, the Kursk, in 2001. The Japanese authorities behaved in a similar fashion after the accident at the nuclear fuel processing facility at Tokaimura (International Atomic Energy Agency, 1999). Denial and duplicity by the authorities are likely to carry penalties and a serious loss of confidence in them is the probable result (Tønnessen et al, 2002).

Two further observations about communicating with the general public after a major incident are that statistics are less persuasive than are case studies, and that individuals are less influenced by statistical probabilities than they are by perceived outcomes (American Psychological Association, 2001). Education - a key element of any public campaign following a biochemical incident - would have an impact on how a community viewed the impact of such an occurrence.

Efforts should be made to develop nonadversarial and collaborative relationships with media personnel before a crisis. As Quigley (2001) has put it most graphically, 'if you don't engage and feed the beast, the beast will eat you'.

\section{THE MENTAL HEALTH SERVICES}

Terrorism is psychological warfare. It is not anticipated that the mental health services would be among the ranks of frontline responders but they should play a signal role in developing major incident plans based on their extensive knowledge of reactions to trauma and of vulnerability and protective factors. An effective plan must be multi-disciplinary and it must be rehearsed regularly under realistic conditions
(Tucker, 1997). Also, they would be expected to treat acute and chronic psychiatric illness and to provide advice and supervision for other agencies.

According to DiGiovanni (1999) there are a number of key roles that the mental health professionals could be expected to fulfill:

(a) advising the authorities on how to manage anxious and distressed individuals;

(b) providing advice for surgical and medical staff about post-traumatic reactions;

(c) helping to determine whether symptoms such as tachycardia, tension, nausea and tremor are normal psychological reactions to stress or are the signs of biological or chemical contamination;

(d) assessing the mental status of those who have suffered physical contamination;

(e) conducting triage to identify those in need of more specialist psychiatric care.

However, mental health personnel need to broaden their concept of trauma to include the physical effects of likely toxic agents and their management, involving the use of decontamination procedures. Similarly, they need to know of the psychological effects of barrier environments and of the wearing of personal respirators and protective clothing.

\section{FORMAL METHODS \\ OF INTERVENTION}

The authorities cannot develop an effective intervention strategy if it is defined merely in terms of physical procedures and knowledge. The psychological dimension to a biochemical event and its effects is allpervasive. More specifically, the physical interventions may themselves give rise to psychological needs and possible problems (Holloway et al, 1997). Barrier environments, quarantine, restricted travel, mass immunisation, decontamination and the destruction of personal clothing and property are experiences totally unfamiliar to most of us in the UK. After the second sarin attack in Tokyo much distress was occasioned by the apparent disregard for survivors' dignity and personal privacy (Holloway et al, 1997). Restrictions on travel, quarantine and isolation of contaminated individuals also have obvious adverse implications for family and social networks, which would represent the first line of support for those caught up in adversity.
There is already evidence that those subject to such a regimen may react adversely even if that incident proves subsequently to be a hoax (Norwood, 2001), and Barbera et al (2001) explore in detail the implications of large-scale quarantine.

\section{Crisis intervention}

The general principles of crisis intervention provide an obvious foundation for an intervention strategy, and subsequent models of early intervention have embraced many of them while extending the intervention strategy.

First used in relation to military combat, 'psychological first aid' has been proposed by Raphael (1986) as an appropriate response in the first phase following major civilian trauma. It represents a coordinated strategy designed to reduce suffering and uncertainty and to harness the healing resources of the survivors without causing iatrogenic harm. Some of these key elements are:

(a) providing survivors with physical and psychological comfort;

(b) protecting them from further harm;

(c) providing accurate information;

(d) re-establishing a sense of order and control (e.g. by restoring the public utilities);

(e) involving survivors, where appropriate, in purposeful activities;

(f) developing or re-establishing, where appropriate, links with family, friends and other survivors;

(g) providing information about helping agencies;

(h) conducting triage to identify individuals at most risk of adverse psychological reactions (guidelines about risk factors have been provided by a number of authorities - Weisæth, 1996; Yehuda, 1999; Klein et al, 2002).

The implementation of psychological first aid will generally rest with the emergency services, the military and hospital personnel. Everly \& Mitchell (2001) present a response strategy, following a terrorist incident, in the fashion of the Ten Commandments. These include: setting up walk-in centres and crisis 'hotlines'; collaboration with the media; enlisting the support of key representatives of political, medical, religious, economic and educational domains; using symbols (e.g. flags and stickers) as a means of enhancing 
community cohesiveness; and initiating rituals to honour the dead, rescuers and helpers and the survivors. Their final 'commandment' is a familiar one, namely, the Galenic principle of 'First, do no harm'. An argument could be advanced for elevating this to the first principle, in deference to recent evidence and concerns about the 'psychonoxious' potential of inappropriate early intervention (e.g. Wessely et al, 1999). Harm can innocently and inadvertently be caused by, for example, retraumatising individuals by premature and/or insensitive re-exposure to reminders of the trauma, by 'medicalising' or 'pathologising' what are normal acute stress responses and by compromising the natural healing potential of individuals, families and communities. With regard to an employer being concerned about liability for 'negligent intervention', a legal authority has emphasised particularly that the debriefer should be adequately trained and reputable and that those to be debriefed should be fully aware of the precise nature and purpose of the debrief (Wheat, 2002: p. 156).

Critical incident stress debriefing was initially introduced as a group method of enabling emergency personnel to adjust to particularly disturbing events and to reduce their likelihood of developing post-traumatic stress disorder (Mitchell \& Everly, 1996). Its popularity resulted in it being widely used for civilians as a single-session intervention following traumatic experiences, a development far removed from the original model. However, its therapeutic or prophylactic value has been questioned (e.g. Wessely et al, 1999; van Emmerick et al, 2002). Evaluative studies are limited in number and can be criticized on methodological grounds, as the review by the British Psychological Society (2002) confirmed. None the less, certainly on the basis of these findings, mandatory debriefing cannot be justified. The debate must be pursued further because there are significant arguments both for and against this intervention (Wessely \& Deahl, 2003) and there are many unanswered questions (Raphael \& Wilson, 2000). There is also a need to evaluate other models of intervention.

Blythe (2002) has produced a helpful manual to assist organisations prepare their staff for a major incident. This is a largely atheoretical practical approach, supplemented with a number of checklists covering a range of communication, health, safety, legal and humanitarian matters. 'Shielding' also has been introduced as a practical public health intervention (Everly, 2002) offering a model for individuals, organisations and communities to minimise the impact of a biochemical terrorist incident, particularly through a self-imposed isolation. The concept of 'stepped care' (Engel et al, 2003) is particularly attractive because it combines the benefits of population-based and individual-based levels of care. Simple community interventions are provided first and, for those individuals with particular medical and specific needs, specialist care is made available later. In other words the psychiatric/ psychological interventions are not offered indiscriminately. A peer support system, the Trauma Risk Management Programme, evolved from the Royal Marines' Stress Trauma Project; this is of particular relevance to hierarchical organisations. It is based on a system of self-help strategies, education, risk assessment and mentoring (C. March, personal communication, 2003).

\section{FIRST RESPONDERS AND CARE-GIVERS: THEIR PREPARATION AND WELFARE}

The threat of a biochemical incident raises questions about the training and preparation of front-line professional responders. As DiGiovanni (1999) has emphasised, there can be no reason to assume that such personnel would be immune from the deleterious psychological effects of a terrorist event of this kind; self-selection and a degree of natural personal resilience do not represent an impermeable barrier to the emotional impact of helping survivors of trauma (e.g. Duckworth, 1986; Figley, 1995; Paton, 1997; Alexander \& Atcheson, 1998; Alexander \& Klein, 2001; McFarlane $\&$ Bookless, 2001). Thus, such personnel who are likely to be faced with the challenge of dealing with a biochemical terrorist incident are entitled to the best available training and preparation, in both physical and psychological terms. The psychoprophylactic value of good preparation and training has been shown already (e.g. Alexander, 1993; Deahl et al, 2000). Their training would need to include not only information about the normal and pathological reactions to extreme stressors but also experience in wearing protective clothing (i.e. 'moon suits') and personal respirators. Barrier clothing can compromise physical function and communication with colleagues and can cause overheating, hyperventilation, fatigue and panic (O’Brien \& Payne, 1993; Krueger, 2001; Ritchie, 2001). The appearance of personnel in protective clothing can be disquieting to the onlooker. For this reason, following the pipe bomb explosion at the Centennial Olympic Park on 27 July 1996 it was agreed that it should not be worn by the FBI while conducting their investigations at the scene (Tucker, 1997).

As was described above by Glass $\&$ Schoch-Spana (2002), the general public also must be considered as key partners in the overall response to a biochemical incident. Similarly, Durodié \& Wessely (2002) and Rowan (2002) advocate that governments should encourage the active cooperaton of the general public (including lay and voluntary bodies) in the preparation of emergency plans. Weaknesses in major incident plans for biochemical attacks have been revealed in field exercises in the USA and following hoaxes (Tucker, 1997). Ashraf (2002) highlighted the fact that, following the terrorist events of 11 September 2001, there were 7622 postal threats involving anthrax throughout Europe. Although anthrax was not used in any of these events, he claimed that they demonstrated that Europe was not fully prepared for widespread terrorist incidents.

\section{POSITIVE OUTCOMES AFTER TRAUMA}

There can be positive gains following involvement in catastrophe, including: a more united community; individuals identifying new strengths; relationships becoming more closely bonded; and life priorities and values being constructively revised (e.g. Joseph et al, 1993; Calhoun \& Tedeschi, 1998; Alexander, 2001). In a 10-year follow-up of the survivors of the Piper Alpha oil platform disaster, Hull et al (2002) found that 22 out of 36 survivors reported positive gains, including closer family relationships, a greater ability to be emotionally expressive and greater financial security after compensation claims were settled. There is the risk that we underestimate the resilience of individuals and communities through what Durodie $\&$ Wessely (2002) describe as the 'risk-obsessed world-view that continuously seeks to catalogue peoples' vulnerabilities'. 


\section{REFERENCES}

Alexander, D. A. (1993) Stress among police body handlers. A long term follow-up. British Journal of Psychiatry, 163, 806-808.

- (200I) Nairobi terrorist bombing. The personal experience of a mental health adviser. International Journal of Emergency Mental Health, 3, 249-257.

_ \& Atcheson, S. F. (1998) Psychiatric aspects of trauma care: survey of nurses and doctors. Psychiatric Bulletin, 22, 132-136.

— \& Klein, S. (200I) Ambulance personnel and critical incidents. Impact of accident and emergency work on emotional well-being. British Journal of Psychiatry, 178, 76-8

_ \& _ (2003) The epidemiology of PTSD and patient vulnerability factors. Psychiatry, 2, 22-25.

Allen, P.T., Archangelskaya, S.T., Belyaev, S.T., et a (1996) Optimisation of health protection of the public following a major nuclear accident: interaction between radiation protection and social and psychological factors. Health Physics, 7I, 763-765.

American Psychological Association (200I) Handling anxiety in the face of the anthrax scare. APA Health Center: Get the facts: Psychology in Daily Life. http: // helping.apa.org/daily/anthrax.html.

Arnon, S. S., Schechter, R., Inglesby, T.V., et al (200I) Botulinum toxin as a biological weapon. Journal of the American Medical Association, 285, 1059-1070.

Ashraf, H. (2002) Europe's response to bioterrorism starts slowly but gathers pace. Lancet, 360, 733-734.

Barbera, J., Macintyre, A., Gostin, L., et al (200I) Large-scale quarantine following biological terrorism in the United States: Scientific examination, logistic and legal limits, and possible consequences. JAMA, 286 27II-27I7

Bartholomew, R. \& Wessely, S. (2002) Protean natur of mass sociogenic illness. From possessed nuns to clinical and biological terrorism fears. British journal of Psychiatry, 180, 300-306.

Baum, A. (1986) Toxins, technology, disaster. In Cataclysms, Crises and Catastrophies (eds G. R. Vanden Bos \& B. K. Bryant), pp. 9-53. Washington, DC American Psychological Association.

Becker, S. M. (200I) Meeting the threat of weapons of mass destruction terrorism. Towards a broader conception of consequence management. Military Medicine, 166 (suppl. 2), 13-16

Blythe, B. T. (2002) Blindsided. A Manager's Guide to Catastrophic Incidents in the Workplace. New York: Portfolio.

British Psychological Society (2002) Psychological Debriefing. Professional Practice Board Working Party Leicester: British Psychological Society.

Calhoun, L. G. \& Tedeschi, R. G. (1998) Posttraumatic growth: future directions. In Posttraumatic Growth: Positive Changes in the Aftermath of Crisis (eds R.G. Tedeschi, C. L. Park \& L. G. Calhoun), pp. 215-238. Mahwah, NJ: Lawrence Erlbaum Associates.

Deahl, M., Srinivasan, M., Jones, N., et al (2000) Preventing psychological trauma in soldiers. The role of operational stress training and psychological debriefing. British Journal of Medical Psychology, 73, 77-85.

DiGiovanni, C. (1999) Domestic terrorism with chemical or biological agents: psychiatric aspects. American Journal of Psychiatry, 10, 1500-1505.

Duckworth, D. (1986) Psychological problems arising from disaster work. Stress Medicine, 2, 315-323.

\section{CLINICAL IMPLICATIONS}

- The threat of a biochemical terrorist incident is a real one, but overreaction by the authorities would be unhelpful and the natural resilience of individuals and communities must not be underestimated.

A degree of preparedness is required, and this should be based upon the best empirical evidence from other trauma research.

- The mental health services would have an important role to play in training, advising and assisting 'front-line responders' as well as helping in the management of those with psychiatric and psychosocial problems.

\section{LIMITATIONS}

- The review had to be selective and there is a bias towards the English-language literature.

- In the absence of robust empirical evidence there had to be some reliance on judgement and informed speculation.

- This review does not specifically address many issues relating to the role of the emergency and hospital services or the military.

DAVID A. ALEXANDER, FRCPsych (Hon.), University Medical School, University of Aberdeen, and Aberdeen Centre for Trauma Research; SUSAN KLEIN, PhD, Aberdeen Centre for Trauma Research, Aberdeen

Correspondence: Professor David A. Alexander, Aberdeen Centre for Trauma Research, Bennachie, Royal Cornhill Hospital, Aberdeen AB25 2ZH, UK

(First received 19 February 2003, final revision 21 July 2003, accepted 31 July 2003)

Durodié, B. \& Wessely S. (2002) Resilience or panic? The public and terrorist attack. Lancet, 360, 1901-1902.

Engel, C. C. (200I) Outbreaks of medically unexplained physical symptoms after military action, terrorist threat or technological disaster. Military Medicine, 166 (suppl. 2), 47-48.

- (2002) Caring for medically unexplained physical symptoms after toxic environmental exposures: effects of contested causation. Environmental Health Perspectives, II0 (suppl. 4), 64I-647.

_, Jaffer, A., Adkins, J., et al (2003) Populationbased healthcare. A model for restoring community health and productivity following a terrorist attack. In Terrorism and Disaster. Individual and Community Health Interventions (eds R. J. Ursano, C. S. Fullerton \& A. E. Norwood), pp. 287-307. New York: Cambridge University Press.

Everly, G. S. (2002) Responding to bioterrorism and psychological toxicity. An introduction to the concept of shielding. International Journal of Emergency Mental Health, 4, 231-233.

— \& Mitchell, J.T. (200I) America under attack: the I0 Commandments' of responding to mass terrorist attacks. International Journal of Emergency Mental Health, 3, 133-135.

Fairbank, J. A., Ebert, L. \& Costello, E. J. (2000) Epidemiology for traumatic events and post-traumatic stress disorder. In Post-traumatic Stress Disorder. Diagnosis, Management and Treatment (eds D. Nutt,
J. R. T. Davidson \& J. Zohar), pp. 17-27. London: Martin Dunitz.

Figley, C. R. (1995) Compassion Fatigue: Coping with Secondary Traumatic Stress Disorder in Those Who Treat the Traumatized. New York: Brunner/Mazel.

Fullerton, C. S. \& Ursano, R. J. (1990) Behavioral and psychological responses to chemical and biological warfare. Military Medicine, I55, 54-58.

Gibson, M. (1998) Order from Chaos. Responding to Traumatic Events. Birmingham: Ventura Press.

Glass, T. \& Schoch-Spana, M. (2002) Bioterrorism and the people: how to vaccinate a city against panic. Clinical Infectious Diseases, 34, 217-223.

Green, B. L., Lindy, J. D. \& Grace, M. C. (1994) Psychological effects of toxic contamination. In Individual and Community Responses to Trauma and Disaster (eds R. J. Ursano, B. G. McCaughey \& B. R. Fullerton), pp. 154-177. Cambridge: Cambridge University Press.

Hadler, N. M. (1996) If you have to prove you are ill, you can't get well. Spine, 2I, 2397-2400.

Harvey, A. G. \& Bryant, R. A. (1999) Acute stress disorder across trauma populations. Journal of Nervous and Mental Disease, 187, 443-446.

Holloway, H. C., Norwood, A. E., Fullerton, C. S., et al (1997) The threat of biological weapons. Prophylaxis and mitigation of psychological and social consequences. Journal of the American Medica Association, 278, 425-427. 
Houts, P., Cleary, P. \& Hu, T. (1988) The Three Mile Island Crisis: Psychological, Social and Economical Impacts on the Surrounding Population. University Park, PA: Pennsylvania State University Press.

\section{Hull, A. M., Alexander, D. A. \& Klein, S. (2002)} Survivors of the Piper Alpha oil platform disaster: long term follow-up study. British Journal of Psychiatry, $\mathbf{~} \mathbf{8} \mathbf{I}$, 433-438.

\section{International Atomic Energy Authority (1999)} Report on the Preliminary Fact-Finding Mission Following the Accident at the Nuclear Fuel Processing Facility in Tokaimura, Japan. Vienna: IAEA.

Janoff-Bulman, R. (1992) Shattered Assumptions: Towards a New Psychology of Trauma. New York: Free Press.

Joseph, S., Williams, R. \& Yule, W. (1993) Changes in outlook following disaster: the preliminary development of a measure to assess positive and negative responses. Journal of Traumatic Stress, 6, 27I-279.

_ ,Williams, R. \& Yule, W. (1997) Understanding Posttraumatic Stress: a Psychosocial Perspective on PTSD and Treatment. Chichester: John Wiley.

Klein, S., Alexander, D. A., Hutchison, J. D., et a (2002) The Aberdeen Trauma Screening Index: an instrument to predict post-accident psychopathology. Psychological Medicine, 32, 863-87I.

Knudson, G. B. (200I) Nuclear, biological, and chemical training in the U.S. Army Reserves: mitigating psychological consequences of weapons of mass destruction. Military Medicine, 166 (suppl. 2), 63-65.

\section{Koopman, C., Classen, C., Cardena, E., et al (1995)}

When disaster strikes, acute stress disorder may follow. Journal of Traumatic Stress, 8, 29-46.

Krueger, G. P. (200I) Psychological and performance effects of chemical-biological protective clothing and equipment. Military Medicine, 166 (suppl. 2), 4I-43.

Lane, H. C., La Montagne, J. \& Fauci, A. S. (200I) Bioterrorism: a clear and present danger. Nature Medicine, 7, |27|-1273.

Laqueur, W. (1999) The New Terrorism: Fanaticism and the Arms of Mass Destruction. New York: Oxford University Press.

McFarlane, A. C. \& Bookless, C. (200I) The effect of PTSD on interpersonal relationships: issues for emergency service workers. Sexual and Relationship Therapy, 16, 261-267.

Mitchell, J.T. \& Everly, G. S. (1996) Critical Incident Stress Debriefing: an Operations Manual for the Prevention of Traumatic Stress among Emergency Services and Disaster Workers (2nd edn). Ellicott City, MD: Chevron Publishing Corporation.

Nocera, A. (2000) Disasters, the media and doctors. Medical Journal of Australia, 172, 137-139.

North, C., Nixon, S., Shariat, S., et al (1999) Psychiatric disorders among survivors of the Oklahoma City bombing. Journal of the American Medical Association, 282, 755-762

Norwood, A. E. (200I) Psychological effects of biological warfare. Military Medicine, 166 (suppl. 2), 27-28.

O'Brien, L. S. (1998) Traumatic Events and Mental Health. Cambridge, UK: Cambridge University Press.
_ \& Payne, R. G. (1993) Prevention and management of panic in personnel facing a chemical threat - lessons from the Gulf War. Journal of the Royal Army Medical Corps, I39, 4I-45.

Pastel, R. H. (200I) Collective behaviors: mass panic and outbreaks of multiple unexplained symptoms. Military Medicine, 166 (suppl. 2), 44-46.

Paton, D. (1997) Post-event support for disaster workers: integrating recovery resources and the recovery environment. Disaster Management and Prevention, 6, 43-49.

Pennebaker, J. W. \& Harber, K. D. (1993) A socia stage model of collective coping: the Loma Prieta Earthquake and the Presian Gulf War. Journal of Social Issues, 49, 125-145.

Petterson, J. C. (1988) Perception vs. reality of radiological impact: the Goiania model. Nuclear News, 31, 84-90.

Pfefferbaum, B., Nixon, S., Tucker, P., et al (1999) Posttraumatic stress response in bereaved children after the Oklahoma City bombing. Journal of the American Academy of Child and Adolescent Psychiatry, 38, 13721379.

Piggin, S. \& Lee, H. (1992) The Mt Kembla Disaster. Sydney: Sydney University Press.

Post, J. M. (2002) The psychology of the terrorist: an interview with Jerrold M. Post. In Trauma Practice in the Wake of September II, 200 (eds S. N. Gold \& J. Faust), pp. 83-100. New York: Haworth Maltreatment and Trauma Press.

Quarantelli, E. L. (1960) Images of withdrawal behavior in disasters: some basic misconceptions. Social Problems, 8, 68-79.

Quigley, C. (200I) Dual-edged sword: dealing with the media before, during, and after a weapon of mass destruction event. Military Medicine, 166 (suppl. 2) 56-58.

Ramalingaswami, V. (200I) Psychosocial effects of the 1994 plague outbreak in Surat, India. Military Medicine, 166 (suppl. 2), 29-30.

Raphael, B. (1986) When Disaster Strikes. How Individuals and Communities Cope with Catastrophe. New York: Basic Books.

— \& Wilson, J. P. (2000) Psychological Debriefing: Theory, Practice and Evidence. Cambridge: Cambridge University Press.

Ritchie, E. C. (200I) Psychological problems associated with mission-oriented protective gear. Military Medicine 166 (suppl. 2), 83-84.

Rowan, F. (2002) Public participation and risk communication. International Journal of Emergency Mental Health, 4, 253-258.

Salib, E. (2003) Suicide terrorism: a case of folie $a$ plusieurs? British Journal of Psychiatry, 182, 475-476.

Schuster, M. A., Stein, B. D., Jaycox, L. H., et al (200I) A national survey of stress reactions after the September II, 200I, terrorist attacks. New England journal of Medicine, 345, 1507-1512.

Shalev, A. (1992) Postraumatic stress disorder among injured survivors of a terrorist attack: predictive value of early intrusion and avoidance symptoms. Journal of Nervous and Mental Diseases, 180, 505-509.
Sims, A. C. P., White, A. C. \& Murphy, T. (1979) Aftermath neurosis: psychological sequelae of the Birmingham bombings in victims not seriously injured. Medicine, Science and the Law, 19, 78-81.

Smith, C. G., Veenhuis, P. E. \& MacCormack, J. N. (2000) Bioterrorism. A new threat with psychological and social sequelae. North Carolina Medical Journal, 6I, 150-163.

Smith, D., Christiansen, E., Vincent, R., et al (1999) Population effects of the bombing of Oklahoma City. Journal of the Oklahoma State Medical Association, 92. 193-198.

Speck, P. (1978) Loss and Grief in Medicine. London: Baillière-Tindall.

Tønnessen, A., Mardberg, B. \& Weisæth, L. (2002) Silent disaster. A European perspective on threat perception from Chernobyl far field fallout. Journal of Traumatic Stress, I5, 453-459.

Tucker, J. B. (1997) National health and medica services responses to incidents of chemical and biological terrorism. JAMA, 278, 362-368.

Tyhurst, J. S. (195I) Individual reactions to community disaster: the natural history of psychiatric phenomena. American Journal of Psychiatry, 107, 764-769.

US Department of Justice (1996) Terrorism in the United States. Washington, DC: Department of Justice.

van der Kolk, B. A., Weisæth, L. \& van der Hart, 0. (1996) Traumatic Stress: the Effects of Overwhelming Experience on Mind, Body, and Society. New York: Guildford Press.

van Emmerik, A. A. P., Kamphuis, J. H., Hulsbosch, A. M., et al (2002) Simple session debriefing after psychological trauma: a meta-analysis. Lancet, $\mathbf{3 6 0}$, 766-77l.

Venkatesh, S. \& Memish, Z. A. (2003) Bioterrorism - a new challenge for public health. International Journal of Antimicrobial Agents, 21, 200-206.

Weisæth, L. (1996) PTSD: Vulnerability and protective factors. In Clinical Psychiatry. Post-Traumatic Stress Disorder (eds E. L. Giller \& L. Weisæth), pp. 217-228. London: Baillière-Tindall.

Wessely, S. (2000) Mass psychogenic illness. New England Journal of Medicine, 342, 129-130.

— \& Deahl, M. (2003) Psychological debriefing is a waste of time. British Journal of Psychiatry, 183, 12-14.

_ , Rose, S. \& Bisson, J. (1999) Brief psychological interventions ('debriefing') for immediate trauma related symptoms and the prevention of post traumatic stress disorder. Cochrane Library, issue 4. Oxford: Update Software.

—, Hyams, K. \& Bartholomew, R. (200I) Psychological implications of chemical and biological weapons. BMJ, 323, 878-879.

Wheat, K. (2002) Napier and Wheat's Recovering Damages for Psychiatric Injury (2nd edn). Oxford, UK: Oxford University Press.

Yehuda, R. (1999) Risk Factors for Posttraumatic Stress Disorder.Washington, DC: American Psychiatric Association. 